\title{
A COMPARATIVE STUDY OF SIMULATION SOFTWARE FOR MODELLING METAL CASTING PROCESSES
}

\author{
Khan, M. A. A. \& Sheikh, A. K. \\ Mechanical Engineering Department, King Fahd University of Petroleum and Minerals, \\ Dhahran, 31261, Saudi Arabia \\ E-Mail: azharali@kfupm.edu.sa
}

\begin{abstract}
Simulation based casting is used in modern metal casting industries to a great extent. A number of software are available for casting simulations which allow methods engineers to model and verify a casting design to maximize yield and minimize defects. However, selection of casting simulation software is critical and necessitates acquiring the knowledge of commercially available software. A comparison amongst the selected casting simulation software has been done in this study. In total, eight software products are selected with a mix of both high end and low end casting simulation packages. The software tools are compared in terms of casting processes simulated, add-on modules (if any), solution methods used, defects prediction, typical clients/users, and advanced simulation capabilities. The results of this study provide a guide for casting industry personnel to select a casting simulation software based on their requirements. It is concluded that need-based selection of casting simulation software is a must to ensure high benefit-cost ratio of simulation based casting. (Received in April 2017, accepted in August 2017. This paper was with the authors 1 month for 2 revisions.)
\end{abstract}

Key Words: Casting Simulation Software, Comparison, Casting Processes, Solution Methods, Casting Defects

\section{INTRODUCTION}

Improvement in casting yield, minimization of defects, and greater strength and fatigue performance of cast products are some of the key challenges in metal casting industry. In order to overcome these challenges and meet the requirement of end users, most of the foundries around the world have adapted the simulation-based casting methodology. Simulation-based casting involves computer-aided modelling of the part to be cast, pattern design, method, process simulation and optimization [1]. The analysis of entire casting process and its optimization in a virtual domain has supplanted the conventional trial-anderror approach by a more scientific proof-of-concept approach for producing high quality cast products. Defects prediction and minimization via simulations have become much easier resulting in high quality and repeatability of the cast products. Also, casting simulations enable to produce these high quality parts at a much faster rate with minimum production cost.

Casting simulations are now extensively utilized for all cast materials, processes, and intricate casting shapes. Fig. 1 represents that high capacity foundries (over 5,000 tons/year) with more than 100 job orders per year needs an in-house casting simulation facility. If two or more foundries are medium capacity with fewer job orders, they can share their casting simulation facilities. In case of small foundries which have less than 10 new job orders per year should either set up a cooperative casting simulation centre or approach casting simulation consultants [2]. A number of casting simulation software tools have been developed by understanding the physical phenomena taking place during casting processes. This software is provided with mathematical models related to physical processes and a database of cast metals and mould materials properties. A relationship between an actual casting process, simulation procedure, modelling of physical phenomena, governing equations, and output variables is illustrated in Fig. 2. 


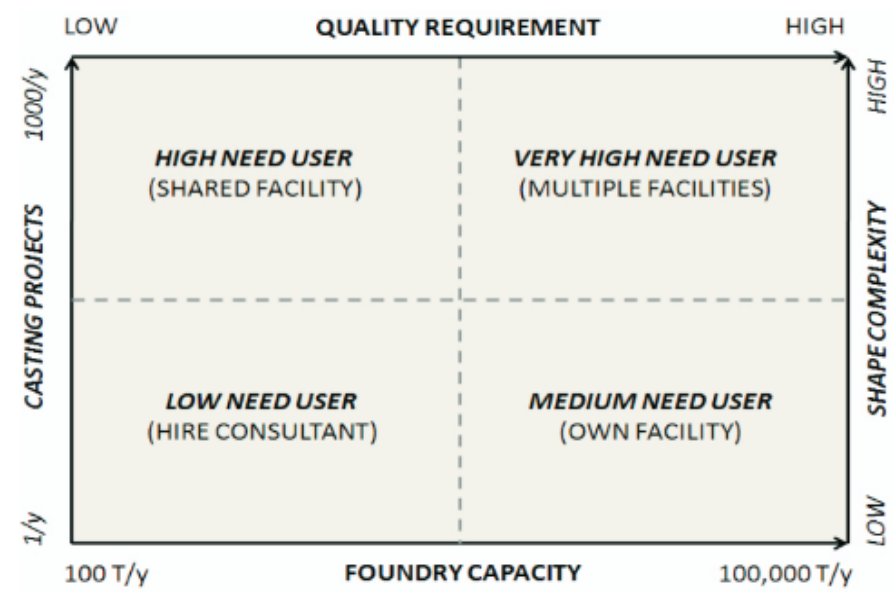

Figure 1: Casting simulation users based on projects, capacity, quality, and shape complexity [2].

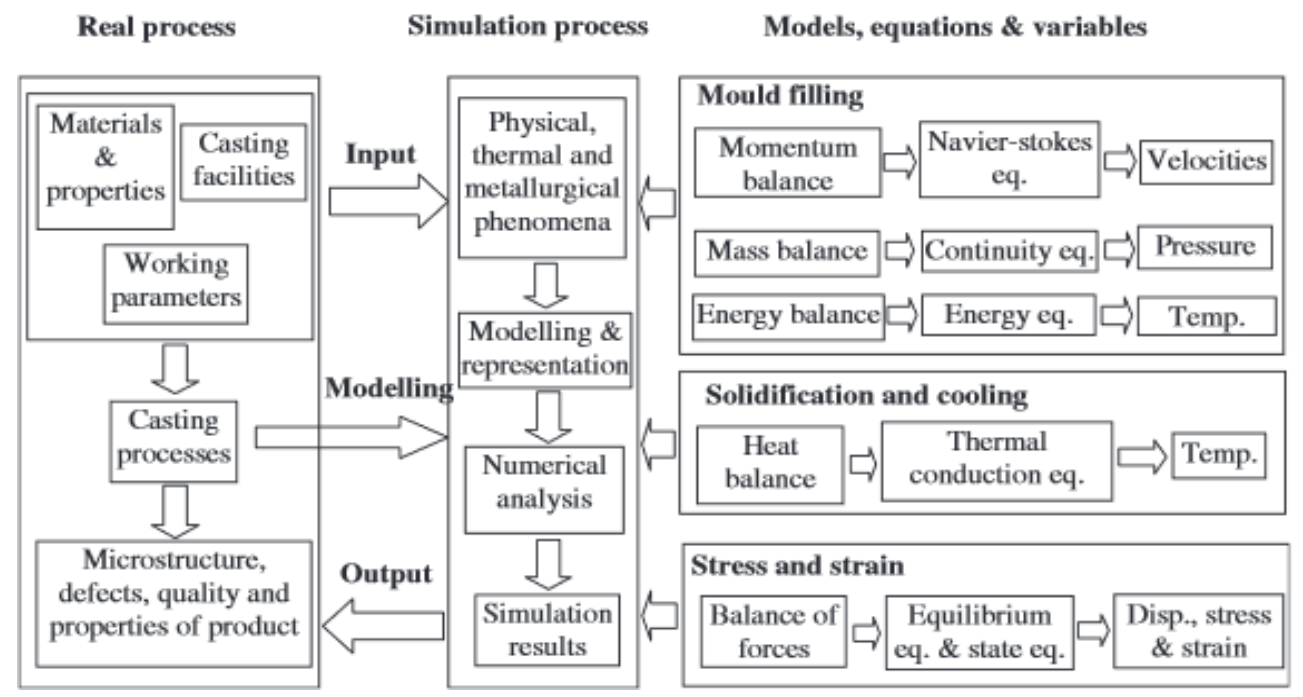

Figure 2: Relationship between the process, modelling, simulation and output variable [3].

From modelling point of view, three important phenomena in any casting process simulation are mould filling, solidification and cooling and stress and strain profile of the cast part. In each of these phenomenon a certain set of governing equations are employed. For example, mould filling is modelled by continuity equation, momentum equation (NavierStokes equation) and the energy equation $[4,5]$. The modelling of solidification properly calls for the solution of energy equation (and the continuity and momentum equations if fluid flow is not neglected) [6]. The main objective of this modelling is to obtain temperature distribution in casting and to identify the solidification behaviour. For stress-strain distribution in castings, equilibrium equations and Hooke's law are generally used to provide the relationship and thus the magnitude of displacement, stress and strain [4].

Each software provides a set of capabilities that can contribute to a better casting design, improved casting yield and higher quality. However, the critical question has remained so far on the selection of a simulation package depending upon the above mentioned requirement of the user. The comparison of available casting simulation software is a promising idea that can help the users to identify the most suitable software. Previously, some work has been done in order to compare these simulation packages. Behera et al. [1] compared two casting simulation software i.e. ProCAST and AutoCAST. The comparison was primarily done in terms of solution method, hardware requirement, user input, steps in simulation, and processing time. Simulation results were validated by a benchmark stepped component. It was reported that AUTOCAST fits more into the foundries without research and development 
division, is more user friendly and does not need any professional training. ProCAST, on the other hand, requires a host of thermo-physical data to set up a simulation; however, it can provide a lot of information such as microstructure, thermal stress, strength, hardness etc. of the cast product.

In another work [7], MAGMASoft and Nova-Solid/Flow are compared for accuracy of results, process of mould filling, solidification process, and prediction of defects and mechanical properties. Results from filling and solidification simulations were found to be in good agreement by using both software tools. Shrinkage defects were predicted by both software tools with a little difference in the location of the shrinkage. Since, the solution methods are different for both packages i.e. finite difference method for MAGMASoft and control volume mesh technology for Nova-Solid/Flow, the simulation took 14 hours by MAGMASoft and 5 hours by Nova-Solid/Flow. Khan et al. [5] reviewed methods of modelling and simulation of metal casting processes with reference to some related case studies using different simulation packages. The study demonstrated underlying mathematical models in the development of simulation software, casting process and optimization protocol, and simulation results related to filling, solidification, and stress profiles in cast products. It was recommended that, for adequate selection of casting simulation software, a comparative study of the commercially available simulation tools should be done.

This study provides a comparison of selected commercially available casting simulation software by providing insight into the available features such as casting processes, solution method, cast metals and mould materials, defects prediction, design and process optimization etc. The next sections explain the methodology adapted for this study. Casting processes are briefly introduced in Section 3 together with the capabilities of each software of modelling these processes. Any add on modules in selected software are also discussed in Section 3. Section 4 reflects on the available solution methods that are employed in casting simulation software. Casting defects together with their prediction by selected simulation packages are discussed in Section 5. Section 6 includes the details of materials database available in each of the simulation software under consideration. Typical consumers of selected casting simulations software and a detailed discussion about the findings obtained in Sections 3 to 6 are presented in Section 7. Conclusions are summarized in the final section of the paper.

\section{METHODOLOGY}

For the purpose of this study, a combination of both high end and low end software is selected. It is aimed to analyse the features and capabilities of these software which can guide metal casting industry individuals to select software that best meets their requirements. In total eight casting simulation software tools are under consideration. Table I lists the names and the vendor addresses of the selected software. The study began with data acquisition about each of the selected software. Following two methods are adapted to collect maximum available data for this software.

1. A questionnaire was prepared and emailed to software companies which ask about software capabilities such as casting processes that can be modelled, add-on modules along with the basic software package, solution method implemented in simulations, defects that can be predicted, materials database, licensing type and cost, typical clients/users of the software etc.

2. Published literature for selected software is collected and all details relevant to this study are obtained. The information in brochures include but not limited to casting processes that can be modelled, steps involved in a simulation, defects that can be predicted, advanced analysis capabilities, optimization in casting design and process, typical clients/users etc. 
Table I: Casting simulation software.

\begin{tabular}{|c|l|}
\hline Casting Simulation Software & \multicolumn{1}{|c|}{ Vendor } \\
\hline AutoCAST & Advances Reasoning Technologies P. Ltd., Mumbai \\
\hline CAPCAST & EKK, Inc., Walled Lake, Michigan, USA \\
\hline CastCAE & CT-Castech Inc. Oy,Espoo, Finland \\
\hline MAGMASoft & MAGMA GmbH, Aachen, Germany \\
\hline Nova-Solid/Flow & Novacast AB, Ronneby, Sweden \\
\hline ProCAST & ESI Group, Paris, France \\
\hline FLOW-3D Cast & Flow Science, Inc., 683 Harkle Rd, Santa Fe, NM 87505, USA \\
\hline SOLIDCast & Finite Solutions Inc., Hamilton, OH, 45013, USA \\
\hline
\end{tabular}

Table II: Casting processes, moulds and metal details [8].

\begin{tabular}{|l|l|c|c|c|}
\hline Casting process & \multicolumn{1}{|c|}{ (a) Mould material } & $\begin{array}{c}\text { (b) Manner } \\
\text { of entry }\end{array}$ & $\begin{array}{c}\text { (c) State of } \\
\text { metal }\end{array}$ & $\begin{array}{c}\text { (d) State of } \\
\text { mould cavity }\end{array}$ \\
\hline Sand casting & $\begin{array}{l}\text { Sand (bonded with clay and } \\
\text { water or chemicals) }\end{array}$ & Gravity & $100 \%$ Liquid & Air \\
\hline Permanent mould & Metal & Gravity & $100 \%$ Liquid & Air \\
\hline Die casting & Metal & Pressure & $100 \%$ Liquid & Air \\
\hline Investment & Ceramic & Gravity & $100 \%$ Liquid & $\begin{array}{c}\text { Air, Vacuum, } \\
\text { Gas }\end{array}$ \\
\hline Lost foam EPC & Sand (unbonded) & Gravity & $100 \%$ Liquid & $\begin{array}{c}\text { Styrofoam, } \\
\text { PMMA }\end{array}$ \\
\hline $\begin{array}{l}\text { Thixocasting } \\
\text { Rheocasting }\end{array}$ & Metal & Pressure & $\begin{array}{c}>50 \% \text { Liquid } \\
\text { Balance Solid }\end{array}$ & Air \\
\hline Cosworth & Sand & Vacuum & $100 \%$ Liquid & Air \\
\hline V process & $\begin{array}{l}\text { Sand (unbonded with vacuum } \\
\text { and enclosing plastic film) }\end{array}$ & Gravity & $100 \%$ Liquid & Air \\
\hline Centrifugal & Metal, graphite & $\begin{array}{c}\text { Centrifugal } \\
\text { forces }\end{array}$ & $100 \%$ Liquid & $\begin{array}{c}\text { Air, Gas } \\
\text { Shroud }\end{array}$ \\
\hline $\begin{array}{l}\text { Ingot - NOT cast } \\
\text { to shape }\end{array}$ & Metal or electro-magnetic field & Gravity & $100 \%$ Liquid & $\begin{array}{c}\text { Air or Gas } \\
\text { Shroud }\end{array}$ \\
\hline
\end{tabular}

\section{CASTING PROCESSES}

Modern metal casting is classified based on a variety of parameters. In fact the casting processes can be distinguished based on (a) the type of mould such as sand, permanent, etc., (b) the flow of molten metal in mould cavity under the action of gravity, vacuum, pressure, (c) state of the metal i.e. fraction of metal which is liquid, (d) the state of the mould cavity itself such as solid, gas, air or vacuum. Table II summarizes some of the casting processes together with the details of mould and metals [8].

Among the selected software, ProCAST, Flow-3D Cast, MAGMASoft, and NovaSolid/Flow, which are actually high end simulation packages, can simulate most of the metal casting processes observed in a foundry. In contrast AutoCAST, SOLIDCast, CastCAE, and CAPCAST simulate relatively fewer processes. Table III lists the casting processes that can be simulated by the selected software. ProCAST is provided with QuikCAST solvers which are fast and efficient solution to deal with the fundamentals of any casting process [9]. For high and low pressure die casting, shop floor conditions can be reproduced by performing several production cycles which enables to study the filling, solidification, intensification pressure effect, cooling channel design and process parameters [9]. Gravity die casting together with tilt pouring process (by defining the axis and velocity of rotation) can be simulated. In terms of investment casting and shell moulding processes, ProCAST is capable 
of generating a mesh that reflects a shell mould. Furthermore, it allows for blending nonuniform shell thickness and creating multiple shell layers. It also takes into account the radiation with view factors, a critical aspect to be considered for high temperature alloys. For sand casting processes, ProCAST provides full flexibility to study the effects of gating and riser system design, filters, chills, exothermic sleeves on processing and quality of cast products. Porosity predictions are much more realistic due to coupled thermal microstructure and porosity calculations including inoculation, where microstructure solver computes growth of different phases and predicts the variations in local density. Some microstructure models available for different cast irons are GI, SGI, CGI, and Ni-Resist [9].

Flow-3D cast is accurate in tracking the flow front progression along with the estimation of temperature profile and locations of potential defects during the filling process. It has special models for simulating lost foam process. Defects such as folds and others associate with trapped foam can be located. For centrifugal casting process, Flow-3D cast has a noninertial reference frame model which defines the rotation and also capable of speed adjustments. An investment casting process can be completely modelled in Flow-3D cast through numerical models. Wax injection, metal filling, solidification of melt, and accurate prediction of defects can be analysed quickly and easily using Flow-3D cast. NovaSolid/Flow simulates flow and solidification during a casting process. Similar to other software, it provides a more greener casting process by increasing the yield and optimizing casting processes. The processes which can be simulated using Nova-Solid/Flow include gravity sand casting, gravity permanent mould, low pressure die casting, high pressure die casting, lost wax method, tilt pouring, counter gravity casting, centrifugal casting and lost foam casting.

MAGMASoft predicts casting quality by simulating mould filling, solidification and cooling, stress/strains, microstructure formation and property distribution. The simulation of any casting process listed in Table III by MAGMASoft is based on it modular structure which includes all functionality required for a comprehensive casting process simulation. A common graphical user interface is available for all modules. One such module is MAGMAfill which provide insights into the flow and filling pattern in the cavity coupled with heat flow in both moulds and dies. Similarly MAGMAsolid deals with casting solidification and cooling. It takes into account liquid and solid contractions to show the feeding of casting and porosity formation. The die casting process mode in the software enables to model cyclic casting processes in permanent moulds. Similar to ProCAST, MAGMAsoft offers full flexibility of investigating the effect of casting designs and process parameters in sand casting processes. Moreover, post-processing in MAGMASoft enables its users to visualize and evaluate the results of filling, solidification and post-solidification stages during any casting process mentioned in Table III.

Table III: Casting processes simulated by selected software [9-16].

\begin{tabular}{|l|c|c|c|c|c|c|c|c|c|c|}
\hline Casting process & $\begin{array}{c}\text { Continuous } \\
\text { casting }\end{array}$ & $\begin{array}{c}\text { High } \\
\text { pressure } \\
\text { die } \\
\text { casting }\end{array}$ & $\begin{array}{c}\text { Low } \\
\text { pressure } \\
\text { die } \\
\text { casting }\end{array}$ & $\begin{array}{c}\text { Gravity } \\
\text { die } \\
\text { casting }\end{array}$ & $\begin{array}{c}\text { Investment } \\
\text { casting, } \\
\text { shell } \\
\text { casting }\end{array}$ & $\begin{array}{c}\text { Sand } \\
\text { casting }\end{array}$ & $\begin{array}{c}\text { Squeeze } \\
\text { casting }\end{array}$ & $\begin{array}{c}\text { Centrifugal } \\
\text { casting }\end{array}$ & $\begin{array}{c}\text { Lost } \\
\text { foam } \\
\text { casting }\end{array}$ & $\begin{array}{c}\text { Tilt } \\
\text { pouring }\end{array}$ \\
\hline AutoCAST & & & & $\checkmark$ & $\checkmark$ & $\checkmark$ & & & & \\
\hline CAPCAST & & $\checkmark$ & $\checkmark$ & & $\checkmark$ & $\checkmark$ & $\checkmark$ & & & \\
\hline CastCAE & & $\checkmark$ & $\checkmark$ & $\checkmark$ & $\checkmark$ & $\checkmark$ & & & & \\
\hline MAGMASoft & & $\checkmark$ & $\checkmark$ & $\checkmark$ & $\checkmark$ & $\checkmark$ & & $\checkmark$ & $\checkmark$ & $\checkmark$ \\
\hline Nova-Solid/Flow & & $\checkmark$ & $\checkmark$ & $\checkmark$ & $\checkmark$ & $\checkmark$ & & $\checkmark$ & $\checkmark$ & $\checkmark$ \\
\hline ProCAST & $\checkmark$ & $\checkmark$ & $\checkmark$ & $\checkmark$ & $\checkmark$ & $\checkmark$ & $\checkmark$ & $\checkmark$ & $\checkmark$ & $\checkmark$ \\
\hline FLOW-3D Cast & $\checkmark$ & $\checkmark$ & $\checkmark$ & $\checkmark$ & $\checkmark$ & $\checkmark$ & $\checkmark$ & $\checkmark$ & $\checkmark$ & $\checkmark$ \\
\hline SOLIDCast & & & $\checkmark$ & $\checkmark$ & $\checkmark$ & $\checkmark$ & & & & \\
\hline
\end{tabular}


Table IV: Add-on modules in selected casting simulation software.

\begin{tabular}{|c|c|c|}
\hline $\begin{array}{c}\text { Casting } \\
\text { simulation } \\
\text { software }\end{array}$ & $\begin{array}{l}\text { Add-on } \\
\text { modules }\end{array}$ & Features \\
\hline AutoCAST & - & Part module, Mold module, Feed Module, Gate module \\
\hline \multirow{4}{*}{ CAPCAST } & CAPPORO & Predictions of location and amount of porosity in castings \\
\hline & WRAFTS & Weighted residual analysis of flow transients \\
\hline & $\begin{array}{l}\text { CAPCAST's } \\
\text { Stress }\end{array}$ & $\begin{array}{l}\text { FE stress and distortion analysis, Fatigue damage assessments of potential } \\
\text { defects }\end{array}$ \\
\hline & CAPOST & CAPCAST Post-processor \\
\hline \multirow{3}{*}{ CastCAE } & CastCHECK & $\begin{array}{l}\text { Important for component designer to avoid manufacturing and quality } \\
\text { problems }\end{array}$ \\
\hline & CastDESIGN & Feeding system design with proper risers and feeder locations \\
\hline & CasrSPEX & Quality specification software for the machine designer \\
\hline \multirow{2}{*}{ MAGMASoft } & - & Pre-processing, simulations, post-processing all together in one package \\
\hline & MAGMALink & Integration of casting simulation results with FEA software \\
\hline \multirow[b]{2}{*}{$\begin{array}{l}\text { Nova- } \\
\text { Solid/Flow }\end{array}$} & NovaStress & Analysis tool to deal with quality issues related to stress \\
\hline & $\begin{array}{l}\text { ATAS } \\
\text { MetStar }\end{array}$ & $\begin{array}{l}\text { Adaptive Thermal Analysis System (analyse, stabilize and optimize } \\
\text { process) }\end{array}$ \\
\hline ProCAST & $\begin{array}{l}\text { Visual- } \\
\text { Environment }\end{array}$ & $\begin{array}{l}\text { Interoperability and link between casting software and other simulation } \\
\text { disciplines. Sub-modules include: } \\
\text { Visual-Mesh, Visual-Cast, Visual-Viewer, and Visual-Process }\end{array}$ \\
\hline FLOW-3D Cast & FlowSight ${ }^{\mathrm{TM}}$ & State-of-the-art visualization and post-processing tool \\
\hline \multirow{2}{*}{ SOLIDCast } & FLOWCast & CFD-based fluid flow analysis \\
\hline & OPTICast & Automatic process optimization \\
\hline
\end{tabular}

Besides these high end software packages, SOLIDCast is capable of simulating low pressure die casting, gravity die casting, investments casting and sand casting. The accuracy of sand casting simulations is improved through combined thermal and volumetric calculations. Shells in investment casting are created automatically and automatic radiation view factors analysis provides accurate simulation results. For permanent mould/die casting simulations accuracy and speed are improved via automatic die cycling. CAPCAST and CastCAE simulate nearly similar processes with an additional capability of simulating squeeze casting in CAPCAST. AutoCAST, on the other hand, can simulate only gravity die casting, investment casting, shell casting and sand casting.

Casting simulation software is usually provided with some add-on modules in addition to basic software packages. The inputs obtained from software developers through designed questionnaire and published brochures provided insight into the add-on modules associated with the selected software for this study. These add-on modules are important as they enable users to analyse various aspects of a casting process in a detailed manner which otherwise are not possible by using the basic package. The add-on modules for the selected software are presented in Table IV along with a short description of each module.

\section{SOLUTION METHODS}

The most common numerical methods implemented in casting simulation software are finite difference method (FDM), finite volume method (FVM), finite element method (FEM), vector element method (VEM), cellular automation method (CA) etc. [17, 18]. Besides standalone use, these methods are sometimes used in combination such as cellular automation finite element (CAFE) method reported by [19], and a hybrid method for casting process simulation by combining FDM and FEM [20]. A summary of solution methods used in selected casting simulation packages is presented in Table V. 
Table V: Solution methods used in selected casting simulation software.

\begin{tabular}{|l|c|c|c|c|}
\hline Solution method & $\begin{array}{c}\text { Finite } \\
\text { Difference } \\
\text { Method }\end{array}$ & $\begin{array}{c}\text { Finite } \\
\text { Volume } \\
\text { Method }\end{array}$ & $\begin{array}{c}\text { Finite } \\
\text { Element } \\
\text { Method }\end{array}$ & $\begin{array}{c}\text { Vector } \\
\text { Element } \\
\text { Method }\end{array}$ \\
\hline AutoCAST & & & & $\checkmark$ \\
\hline CAPCAST & & & $\checkmark$ & \\
\hline CastCAE & & $\checkmark$ & & \\
\hline MAGMASoft & $\checkmark$ & & & \\
\hline Nova-Solid/Flow & & $\checkmark$ & & \\
\hline ProCAST & & & $\checkmark$ & \\
\hline FLOW-3D Cast & $\checkmark$ & & $\checkmark$ & \\
\hline SOLIDCast & $\checkmark$ & & & \\
\hline
\end{tabular}

Finite Difference Method: It is a numerical method where a complex problem is solved by discretizing the complete region of problem (also known as domain) into a finite number of small portions (also known as control volumes). Material properties are assumed to be constant throughout the volume. Therefore, for high accuracy of the results, the domain should be divided into maximum no. of control volumes possible taking into account the computational time. FDM is a differential scheme which is the approximation of Taylor series expansion. Calculations are iterative and done at a predetermined time-step. The results can be stored at the end of each time-step or after a pre-determined numbers of steps [4]. Among the selected software for this study, MAGMASoft, FLOW-3D Cast, and SOLIDCast are based on FDM. MAGMASoft solves heat and mass transfer on a rectangular grid which is reflected by the rectangular cubes on the outer side of the model. Besides the filling behaviour in the mould/die, it also provides information about casting related features such as premature solidification, air entrapment, velocity distribution, gating and runner system effectiveness etc. FLOW-3D Cast tracks flow front progression of the melt through Volume of Fluid (VOF) technique and models intricate parts by the Fractional Area/Volume Ratios (FAVOR) technique [10]. Simple structured rectangular grids are easy to generate and offers various features such as improved free-surface flow accuracy, less memory consumption, and reasonable numerical approximations [10]. However, a limitation in the rectangular grids is the artificially introduced stairstep artifacts along the curved and sloping boundaries. Also, VOF technique for modelling the free surfaces results in artificial diffusion and mass conservation problems in these regions [21]. Mesh and geometry are independent which simplifies the meshing process together with time saving in pre-processing of a simulation. This approach also provides the flexibility of testing different designs without changing the mesh, thus making it easier for its users. SOLIDCast has an add-on module FLOWCast which is a computational fluid dynamics solver based on the Navier-Stokes equation for fluid flow [11]. Using FLOWCast the fluid velocity, fluid pressure and progressive temperature can be viewed from any desired angle during mould filling. Models and meshes generated in SOLIDCast are compatible with FLOWCast. The simulation begins with modelling the casting design in SOLIDCast, meshing, running FLOWCast to simulate mould filling, and then results from FLOWCast are used in SOLIDCast to model the solidification behaviour of the casting.

Finite Volume Method: Unlike FDM, FVM is an integral scheme. Although the idea of discretizing the domain into small control volumes remains the same, the use of integral formulations is advantageous in treating the Neumann boundary conditions as well as that of discontinuous source terms due to their reduced requirements on the regularity or smoothness of the solution. Nova-Solid/Flow and CASTCAE are two software tools that utilize FVM approach in solving a casting problem. Nova-Solid/Flow has a control on mesh elements at the borders of casting. With cubic elements inside and border cells on the boundary of 
casting, the simulations are much faster and accurate. FVM is used throughout NovaSolid/Flow filling and solidification simulations. The height/width of metal front is calculated during filling. Also, it provides filling of necessary fraction of a cell instead of filling cell by cell as observed in FDM [13]. CASTCAE also utilizes FVM and generates rectangular mesh and provides reliable results even with the rough meshes.

Finite Element Method: FEM discretizes the complete domain of the problem into small pieces; however, they are now termed as elements. Each element is made up of nodes (corner points) and edges, which store material properties to be used in computation. Solution is done by using these values to determine a quantity for these specific points (also known as Gauss points) within the elements. The position of these points in elements is a function of the integration applied, initial coordinates of the nodes, and the element shape [4]. Values of variables, which are considered to be constant in FDM/FVM across the elements, are calculated using some interpolation function. However, the treatment of time in an iterative and step-wise manner is similar to FDM/FVM. ProCAST and CAPCAST from the selected software are based on FEM technology. ProCAST is provided with a mesh generator which creates a block-structured mesh for filling and solidification simulations. Another important feature in the software is layered mesh option which generates coincident and non-coincident meshes resulting in increased accuracy of results. Surface mesh assemblies and Boolean operations can also be performed in ProCAST [9]. CAPCAST is also provided with an automatic and robust mesh generator known as KENT [14]. It creates a multi-component finite element model from STL files. A solid model of the casting which is normally developed in most of the foundries can be imported. Next, all necessary components of the mould can be incorporated and all thermal interactions can be modelled. Automatic coarsening of the mesh saves simulation set up and computational time. For improved accuracy, the mould components near the casting are discretized in a way similar to casting i.e. fine mesh whereas rest of the domain is discretized with a reasonable mesh size.

Vector Element Method: This approach to casting simulations is based on determining the largest thermal gradient at any point inside the casting, which is given by the vector sum of flux vectors in all directions from that point [22]. The volume of casting is divided into numerous pyramidal sectors from the considered point. For each of these pyramidal sectors, there exists a small solid angle. The heat content (which is proportional to volume) and the surface area or cooling is calculated for each sector to compute flux vector. The computation is repeated by taking a step along the direction of resultant flux vector, unless the resultant flux vector becomes zero (or close to zero for the purpose of computation). The location of hotspot is the last location and the feed metal path is considered to be the curve alongside which the repetitions are done. It is possible to identify various hotspots in casting if the computation is started from numerous seed points located at different regions of casting. Vector element method is relatively simple when compared to other numerical techniques but provides reliable and robust results [23, 24]. Unlike FEM or FDM methods, VEM rectifies small errors while computing flux vector at any point by automatically correcting them in subsequent repetitions. Moreover, VEM requires less memory and is also faster. AUTOCAST, among the list of selected software, is based on this method.

\section{DEFECTS PREDICTION}

Casting defects need to be predicted, visualized and fixed computationally before actual castings are produced in foundry. Defects in castings can be broadly categorized as (a) filling related defects, (b) shape related defects (c) thermal defects, and defects by appearance [25]. These four type of defects along with their causes and remedies are presented elsewhere [26]. The defect prediction capabilities of selected casting simulation software are discussed in this 
section. A summary of most common casting defects predicted by selected simulation packages is presented in Table VI.

Porosity, cold shuts, misruns and shrinkage defects can be predicted by all software irrespective of their low end or high end nature. However, for more detailed defects analysis, ProCAST, MAGMASoft, and CAPCAST are found to be more suitable. For example these software is capable of computing the grain structure, including columnar to equiaxed transitions, for any dendritic alloy. The grain structure module in ProCAST is based on cellular automation finite element (CAFE) technique which is already discussed in Section 4. Nova-Solid/Flow and Flow-3D cast are comparable in predicting the casting defects; however, SOLIDCast does not provide any information about thermal defects in castings. Irrespective of the types of defects predicted, each of the selected software provides the opportunity to re-work and modify the method design and process parameters within the same environment to eliminate the defects and produce high quality castings.

Table VI: Defects predicted by selected casting simulation software [9-16].

\begin{tabular}{|l|c|c|c|c|c|c|c|c|c|}
\hline Casting defects & Porosity & $\begin{array}{c}\text { Cold } \\
\text { shuts, } \\
\text { misruns }\end{array}$ & $\begin{array}{c}\text { Air } \\
\text { entrapment } \\
\text { and oxide } \\
\text { skins }\end{array}$ & Shrinkage & $\begin{array}{c}\text { Hot } \\
\text { tearing } \\
\text { and } \\
\text { cracks }\end{array}$ & $\begin{array}{c}\text { Thermal } \\
\text { stress }\end{array}$ & $\begin{array}{c}\text { Blow } \\
\text { holes }\end{array}$ & $\begin{array}{c}\text { Hard } \\
\text { zones }\end{array}$ & $\begin{array}{c}\text { Microstructure } \\
\text { anomalies }\end{array}$ \\
\hline AutoCAST & $\checkmark$ & $\checkmark$ & & & & & $\checkmark$ & $\checkmark$ & \\
\hline CAPCAST & $\checkmark$ & $\checkmark$ & $\checkmark$ & $\checkmark$ & $\checkmark$ & $\checkmark$ & $\checkmark$ & $\checkmark$ & $\checkmark$ \\
\hline CastCAE & $\checkmark$ & $\checkmark$ & & $\checkmark$ & & & & & \\
\hline MAGMASoft & $\checkmark$ & $\checkmark$ & $\checkmark$ & $\checkmark$ & $\checkmark$ & $\checkmark$ & $\checkmark$ & $\checkmark$ & $\checkmark$ \\
\hline Nova-Solid/Flow & $\checkmark$ & $\checkmark$ & $\checkmark$ & $\checkmark$ & $\checkmark$ & $\checkmark$ & & & \\
\hline ProCAST & $\checkmark$ & $\checkmark$ & $\checkmark$ & $\checkmark$ & $\checkmark$ & $\checkmark$ & $\checkmark$ & $\checkmark$ & $\checkmark$ \\
\hline FLOW-3D Cast & $\checkmark$ & $\checkmark$ & $\checkmark$ & $\checkmark$ & & $\checkmark$ & & & \\
\hline SOLIDCast & $\checkmark$ & $\checkmark$ & & $\checkmark$ & $\checkmark$ & & & & \\
\hline
\end{tabular}

Table VII: Material database available in selected casting simulation software.

\begin{tabular}{|l|c|c|c|c|c|}
\hline \multicolumn{1}{|c|}{ Cast materials } & $\begin{array}{c}\text { Cast and } \\
\text { ductile irons }\end{array}$ & $\begin{array}{c}\text { Plain and } \\
\text { alloy steels }\end{array}$ & $\begin{array}{c}\text { Aluminium, } \\
\text { copper, magnesium } \\
\text { and zinc alloys }\end{array}$ & $\begin{array}{c}\text { Precious and } \\
\text { super alloys }\end{array}$ & Others \\
\hline AutoCAST & $\checkmark$ & $\checkmark$ & $\checkmark$ & $\checkmark$ & \\
\hline CAPCAST & $\checkmark$ & $\checkmark$ & $\checkmark$ & $\checkmark$ & \\
\hline CastCAE & $\checkmark$ & $\checkmark$ & $\checkmark$ & $\checkmark$ & \\
\hline MAGMASoft & $\checkmark$ & $\checkmark$ & $\checkmark$ & $\checkmark$ & (a) \\
\hline Nova-Solid/Flow & $\checkmark$ & $\checkmark$ & $\checkmark$ & $\checkmark$ & (a) \\
\hline ProCAST & $\checkmark$ & $\checkmark$ & $\checkmark$ & $\checkmark$ & (a) \\
\hline FLOW-3D Cast & $\checkmark$ & $\checkmark$ & $\checkmark$ & & (a),(b) \\
\hline SOLIDCast & $\checkmark$ & $\checkmark$ & $\checkmark$ & $\checkmark$ & (a) \\
\hline
\end{tabular}

(a) Any casting alloy properties can be entered to the database

(b) Material properties from JMATPRO are also available at a nominal cost

\section{MATERIALS DATABASE}

One of the main strengths of any casting simulation software is its materials database. Simulating actual casting process accurately relies on the availability of cast metals, mould and core materials in the materials database of the software. Owing to the fact that this is a prime consideration in casting simulations, most of the simulation packages provide a very vast materials database as shown in Table VII. The selected software for this study provides material properties of cast metals such as cast and ductile irons, plain and alloy steels. Aluminium, copper, magnesium, and zinc alloys, precious and super alloys such as nickel, chromium, and titanium based alloys. High end software especially MAGMASoft and 
ProCAST also provides most commonly used mould and core materials. Also, MAGMASoft, ProCAST, Nova-Solid/Flow and SolidCAST have an open database system which allows for any other casting alloy properties to be entered in the database. Flow-3D cast have a limited database for aluminium, steel, zinc, magnesium and iron, however, it offers material properties from JMATPRO at very nominal cost.

\section{DISCUSSION}

Casting simulation software is utilized in more or less all metal casting industries. Typical clients of this software include (a) Foundries, (b) Academic institutions, (c) Research and development organizations, and (d) Original equipment manufacturers. In this sections, some of the clients of selected casting simulations software are presented the data of which are collected from published brochure. Table VIII provides a summary of typical clients/users of the selected simulations software.

One important aspect in the high end software such as ProCAST and MAGMASoft is the autonomous optimization of castings. It refers to an automatic trial and error approach in a virtual domain based on user-defined goals. Computer simulates all possible combinations and makes decision to improve materials properties and/or process parameters. This approach saves a lot of time due to limited human interaction in contrast to conventional simulations where each simulation has to be set by user based on improved design and process conditions.

Table VIII: Users/Clients of selected casting simulation software.

\begin{tabular}{|c|c|c|c|}
\hline $\begin{array}{c}\text { Casting simulation } \\
\text { software }\end{array}$ & Clients/Users & Industry & Country \\
\hline \multirow{4}{*}{ CastCAE } & VTT Manufacturing Technology & Manufacturing & Finland \\
\hline & Meehanite German office & Foundry & Germany \\
\hline & Valmet - Jyväskylä Foundry & Foundry & Finland \\
\hline & Roslagsgjuterierna $\mathrm{AB}$ & Manufacturing & Sweden \\
\hline \multirow{4}{*}{ MAGMASoft } & Aallied Die Casting & Die Castings & United States \\
\hline & Masabik Foundry & Foundry & Saudi Arabia \\
\hline & $\begin{array}{l}\text { King Fahd University of } \\
\text { Petroleum and Minerals }\end{array}$ & Academic User & Saudi Arabia \\
\hline & More than 1600 users worldwide & Miscellaneous & - \\
\hline \multirow{2}{*}{ Nova-Solid/Flow } & Grundfos & Pump Manufacturer & Denmark \\
\hline & Oskar Frech GmbH \& Co. & Die Castings & Germany \\
\hline \multirow{5}{*}{ ProCAST } & DSB EURO s.r.o & Foundry & Czech Republic \\
\hline & $\begin{array}{l}\text { Vulcan SFM, Sheffield } \\
\text { Forgemasters International Ltd. }\end{array}$ & Design and Manufacturing & United Kingdom \\
\hline & EMA Rolls Royce & Investment casting foundry & Italy \\
\hline & Zheng Yang Mould Manufactory & Tool and die-maker & Taiwan \\
\hline & Inasmet-Tecnilia & Foundry (Large Castings) & Spain \\
\hline \multirow{3}{*}{ FLOW-3D Cast } & Hellebusch Tool \& Die Inc. & Injection Moulds and Dies & United States \\
\hline & Teksid S.P.A & Castings (Automotive industry) & Italy \\
\hline & BMW Group & Automotive & Germany \\
\hline SOLIDCast & $\begin{array}{l}\text { More than } 750 \text { licenses } \\
\text { purchased in over } 50 \text { countries }\end{array}$ & Miscellaneous & - \\
\hline
\end{tabular}

ProCAST is also capable of doing advanced analysis that directly affects the end properties of as cast products. One such advanced analysis by ProCAST is the calculation of types and volume fraction of phases present, grain size and shape which determines the mechanical properties of a cast product. Further, it uses Time-Temperature-Transformation (TTT) and/or Continuous Cooling Transformation (CCT) diagrams to simulate the solid state phase transformation and the resulting mechanical properties during heat treatment. Macrosegregation can also be calculated using microstructure solver. Unlike other simulation 
packages which limit the porosity predictions to shrinkage porosity, ProCAST can model shrinkage as well as gas porosity. It is also provided with a gas segregation model which properly treats the solubility limit and pore nucleation [9].

FLOW-3D Cast is available in three different packages: Basic, Extended and Advanced. The basic package capabilities includes, but not limited to, multi-block meshing, ladle pouring with provision of rotation about an axis, filling taking into account the viscous, turbulence, and surface tension effects, solidification and heat transfer, comprehensive database for cast and mould materials, chills and isolating sleeves, identifying oxide formation and defects, filling and solidification related porosity, particle modelling etc. The extended version of the software has all Basic features together with unlimited mesh blocks for improved accuracy, trapped gases and venting effects, optimization of shot sleeve performance, lost foam casting and foam defects, prediction of cavitation to determine mould/die erosion, permeable mould model, six degrees of freedom for defining shot sleeve motion and ladle pouring motion. Besides Basic and Extended features, the Advanced version also includes binary segregation, core gas release and related defects, sand core blowing, enhanced viscous effects including non-Newtonian viscosity, shear thinning/thickening, and thixotropic flows, thermal and mechanically induced distortions and stresses [10]. It is claimed that the free-surface solution in FLOW-3D Cast is far more accurate than any other commercially available CFD packages.

SOLIDCast, as discussed earlier, uses combined thermal/volumetric calculations, including graphite expansion in cast iron, which gives superior predictions for feeding of shrinkage. Built-in gating and riser design functions take simulation results from an unrigged model and help the user to design an effective rigging system. Site licensing and low cost allow all students and engineers to take direct advantage of simulation technology, while obtaining accurate results. Finite Solutions Inc.'s primary technical developers have operating foundry experience, which helps to guide system development in a very practical and results oriented way. To sum up, the simulation package is fast, economical and accurate.

Nova-Solid/Flow comes with multi-meshing which uses different meshes during filling and then in solidification. An interesting feature in this software is Good Guy's Index, which computes technical and environmental aspects of a casting by comparing different simulations and assigning a score. It can provide average values for austenite, graphite and cementite for cast irons. Irregular mesh of the moulds can be generated taking into account the fineness of the mesh in critical regions. Computation of stress is done based on full contact task. The software is also capable of parameter optimization to obtain defect-free high quality castings.

MAGMASoft which is also a high end software has dedicated modules for each cast materials such as MAGMAiron, MAGMAsteel, and MAGMAnonferrous. MAGMAiron uses microscopic kinetic growth models for predicting the solidification sequence of cast iron alloys. Final microstructure and thus the mechanical properties of the cast iron products can also be predicted. MAGMAsteel computes velocities and pressures in both the liquid metal and the mushy zones due to thermal and solutal natural convection. Velocities are then coupled with an advanced microsegregation model at the dendritic scale to track the redistribution of the elements in the alloy and predict macrosegregation. MAGMAnonferrous also utilizes the kinetic growth models for determining the microstructure development during solidification of aluminium alloys with detailed consideration of alloy chemistry, metallurgy and processing. MAGMAsoft also provides additional modules based on processes such as MAGMAhpdc and MAGMAlpdc for high pressure and low pressure die castings respectively, MAGMAcore+mold and MAGMAdielife. Moreover, MAGMA HT thermal and MAGMAstress are used for heat treatment and stresses in the component after ejection. In addition to all these modules, MAGMAsoft provides the opportunity to exchange results of 
casting simulations to finite element packages through MAGMAlink for evaluation of mechanical performance and residual life of the cast products in service.

CAPCAST, based on FEM is reported to be more accurate in modelling any casting process with minimum computational requirements. The software is able to simulate complex mould geometries with modest computational facilities. Owing to quick simulations turnaround time, it is possible to try and reach a near-optimal casting design in minimum time [14]. However, it must be realized that the optimization capabilities of this software cannot be compared with the autonomous optimization of ProCAST and MAGMASoft discussed above. CastCAE is also found to be popular in metal casting industries. As reported by CastCAE users, some advantages of using this simulation packages are energy savings of up to $6 \%$, improvements in product quality, less re-melting and re-finishing, maximum production with minimum lead time, wastage and weight reduction of up to $84 \%$ and $5 \%$ respectively. The software usually pays back in one to two years from its purchase. AUTOCAST being a low end software is limited in use and results, however, some key advantages of this simulation package includes coupled mould filling and casting solidification computations with minimal user input, lower rejection rate, quality assurance, yield improvement, faster turnaround [12].

\section{CONCLUSIONS}

The key conclusions from this study are as follows:

- Casting simulation software simulates most of the casting processes; however, the reliability of results depends upon how accurately the simulation is set up by defining the material properties, meshing, boundary conditions etc.

- Most of the software is based on FDM, FVM or FEM solutions. FEM improves simulation time by $10 \%$ because it needs less number of cells to define casting geometry as compared to FDM and FVM.

- Prediction of defects is a real strength of these software because defects can be eliminated using these software resulting in waste minimization of molten metal which is significant in conventional trial and error approach of metal casting.

- All selected software tools are provided with comprehensive materials databases (which can be modified) for cast metals, moulds and cores.

- Foundries, academic institutions, research and development organizations, and original equipment manufacturers are the typical consumers of casting simulation packages.

- Based on comparison in selected areas, ProCAST, MAGMASoft, Nova-Solid/flow, CAPCAST and Flow-3D can be considered as top notch software tools whereas, CASTCAE, SOLIDCast, and AUTOCAST are available with limited features. Hence, the need based selection of any casting simulation package must be ensured by any user to maximize the benefit-cost ratio of simulation based casting.

\section{ACKNOWLEDGEMENTS}

The authors would like to acknowledge the support provided by King Fahd University of Petroleum and Minerals (KFUPM) and National Science, Technology and Innovation Plan (NSTIP) in this research under Project No. 14-ADV890-04-R.

\section{REFERENCES}

[1] Behera, R.; Das, S.; Dutta, A.; Chatterjee, D.; Sutradhar, G. (2010). Comparative evaluation of usability of FEM- and VEM-based casting simulation software, $58^{\text {th }}$ Indian Foundry Congress, 31-39 
[2] Ravi, B. (2010). Casting simulation - Best practices, Transactions of $58^{\text {th }}$ Indian Foundry Congress, 19-29

[3] Fu, M. W.; Yong, M. S. (2009). Simulation-enabled casting product defect prediction in die casting process, International Journal of Production Research, Vol. 47, No. 18, 5203-5216, doi:10.1080/00207540801935616

[4] Jolly, M. (2003). Castings (Ch. 1.18), Milne, I.; Ritchie, R.; Karihaloo, B. L. (Eds.), Comprehensive Structural Integrity, Vol. 1, Elsevier, Pergamon, Amsterdam, 377-466

[5] Khan, M. A. A.; Sheikh, A. K. (2016). Simulation tools in enhancing metal casting productivity and quality: a review, Proceedings of the Institution of Mechanical Engineers, Part B: Journal of Engineering Manufacture, Vol. 230, No. 10, 1799-1817, doi:10.1177/0954405416640183

[6] Hattel, J. H. (Ed.), (2005). Fundamentals of Numerical Modelling of Casting Processes, Polyteknisk Forlag, Lyngby

[7] Vasková, I.; Fecko, D.; Eperješi, L. (2011). Comparison of simulation programs MAGMASOFT and NOVAFLOW\&SOLID in terms of results accuracy, Archives of Foundry Engineering, Vol. 11 , No. 1, 51-54

[8] Rundman, K. B. (2000). Metal casting, Department of Material Science and Engineering, Michigan Technological University, Houghton, 17-19

[9] ESI Group (2011). Casting Simulation Suite - ProCAST / QuikCAST, ESI Group, Paris

[10] FLOW Science (2015). Flow-3D-Cast-Brochure, FLOW Science, Santa Fe

[11] Finite Solutions (2015). SOLIDCast-Brochure, Finite Solutions Inc., Slinger

[12] AutoCAST (2015). Nothing is Easy in a Foundry Except Methoding and Simulation with AutoCAST, 3D Foundry Tech Pvt. Ltd., Mumbai

[13] NOVACAST systems (2015). Nova-Solid/Flow Brochure, NOVACAST, Ronneby

[14] EKK, Inc. Metal Casting Process Simulation Software and Services, from http://ekkinc.com/, accessed on 22-12-2015

[15] MAGMASOFT. Casting Process Optimization with MAGMA, MAGMASOFT, and MAGMA5, from $h t t p: / / w w w . m a g m a s o f t . c o m / e n /$ accessed on 22-12-2015

[16] CASTech. Home of Virtual Casting, CT-Castech Inc. Oy, Kerava

[17] Lewis, R. W.; Ravindran, K. (2000). Finite element simulation of metal casting, International Journal for Numerical Methods in Engineering, Vol. 47, No. 1-3, 29-59, doi:10.1002/(SICI) 1097-0207(20000110/30)47:1/3<29::AID-NME760>3.0.CO;2-X

[18] Cleary, P.; Ha, J.; Alguine, V.; Nguyen, T. (2002). Flow modelling in casting processes, Applied Mathematical Modelling, Vol. 26, No. 2, 171-190, doi:10.1016/S0307-904X(01)00054-3

[19] Rappaz, M.; Rettenmayr, M. (1998). Simulation of solidification, Current Opinion in Solid State and Materials Science, Vol. 3, No. 3, 275-282, doi:10.1016/S1359-0286(98)80103-4

[20] Si, H.-M.; Cho, C.; Kwahk, S.-Y. (2003). A hybrid method for casting process simulation by combining FDM and FEM with an efficient data conversion algorithm, Journal of Materials Processing Technology, Vol. 133, No. 3, 311-321, doi:10.1016/S0924-0136(02)01008-7

[21] Ha, J.; Cleary, P. W.; Prakash, M.; Alguine, V.; Nguyen, T.; Scott, C. (2003). SPH, MAGMAsoft and Water Analogue modellings of die filling of a servo piston, Third International Conference on CFD in the Minerals and Process Industries, 587-592

[22] Amin, L. D.; Patel, S.; Mishra, P.; Joshi, D. (2014). Rapid development of industrial castings using computer simulation, Indian Foundry Journal, Vol. 60, No. 8, 40-42

[23] Ravi, B. (2005). Metal Casting: Computer-Aided Design and Analysis, Prentice-Hall of India, New Delhi

[24] Sutaria, M.; Ravi, B. (2014). Computation of casting solidification feed-paths using gradient vector method with various boundary conditions, The International Journal of Advanced Manufacturing Technology, Vol. 75, No. 1-4, 209-223, doi:10.1007/s00170-014-6049-3

[25] Rajkolhe, R.; Khan, J. G. (2014). Defects, causes and their remedies in casting process: a review, International Journal of Research in Advent Technology, Vol. 2, No. 3, 375-383

[26] Khan, M. A. A.; Sheikh, A. K.; Al-Shaer, B. S. (2017). Evolution of Metal Casting Technologies, Springer International Publishing, Cham 